\title{
Research on the Bottlenecks and Strategy of Agricultural Export in the Background of "Internet +"
}

\author{
Zhang rui \\ Jilin Business and Technology College \\ Zhengyang street No.1761,Ivyuan district, Changchun, China \\ 333889610@qq.com
}

Keywords: "Internet +", Agricultural Products Export, Bottlenecks, Strategy

\begin{abstract}
Large agricultural trade is a matter of national food security, world food balance surplus and deficiency; little affected the people's daily diet, optimize the diet. Through the expansion of exports of agricultural products, help speed up the industrialization process of agriculture, promote agricultural science and technology innovation and promotion, promote the transfer of rural surplus labor, the realization of farmers' income. "Internet $+" 2.0$ is an innovative new form of Internet development under the new format, the morphological evolution of the Internet 2.0 social innovation driven by knowledge and the birth of a new form of economic and social development. Agriculture seems farthest from the Internet, but the potential for the "Internet + agriculture" is huge. Agriculture is the most traditional Chinese basic industries, an urgent need to enhance the efficiency of agricultural production with digital technology, through information technology to land soil fertility, climate and other large data analysis, and thus provide planting, fertilizing related solutions, greatly enhance agricultural production efficiency and further expand the export of agricultural products with comparative advantages.
\end{abstract}

\section{Introduction}

Agriculture is the foundation of human existence and development of agricultural production in relation to people's livelihood, so that the agricultural trade position in international trade important. Increase exports of agricultural products to better play to the comparative advantage in agriculture, help to foster a number of competitive agricultural export enterprises, making full use of both domestic and overseas markets, rational integration of domestic and foreign resources, and in the fierce international competition in a place. Improve the international competitiveness of agricultural products, the agricultural economy and consolidate the foundation of agriculture is crucial. Through the expansion of exports of agricultural products, help speed up the industrialization process of agriculture, promote agricultural science and technology innovation and promotion, promote the transfer of rural surplus labor, the realization of farmers' income. With the continuous expansion of the rapid economic growth and domestic consumer demand, imports rose steadily, resulting in agricultural trade since 2004 by a surplus to a deficit. 2011, China's agricultural trade deficit reached $\$ 33.78$ billion, an increase of $46.6 \%$. Further expand exports of agricultural products with comparative advantages can effectively suppress China's agricultural trade deficit scale, and gradually achieve a basic balance of agricultural trade, to ensure the smooth operation of the national economy is of great strategic significance.

"Internet + " is to further the practice of thinking of the outcome of the Internet, it represents a 
kind of advanced productive forces, promote economic patterns evolve constantly occur. Thus boosting the social and economic vitality entity, provide a vast network platform for reform, innovation and development. Popular, "Internet +" is the "Internet + various traditional industries", but this is not a simple sum of the two, but the use of information and communication technologies and the Internet platform for Internet and traditional industries depth of integration, the creation of new Development of ecology. It represents a new form of society, that is fully optimized and integrated role of the Internet in the allocation of social resources, and the innovations in the depth of Internet integration among all areas of economic, social, and enhance innovation and productivity of the whole society to form More extensive Internet infrastructure and implementation tools of a new form of economic development. For decades, the "Internet + " has been transformed and influenced a number of industries, the current public familiar with the "Internet + ", Internet banking, online travel, online video, online real estate and other industries are "Internet +" masterpiece [1].

How to use the "Internet + " this new marketing tool in improving the process of agricultural trade to achieve common business information bottlenecks, thereby promoting unity of the agricultural market within the country formed, and thus solve the agricultural trade by poor flow of information sales of agricultural products due to difficulties and improve the prevailing contradictions of China's agricultural households increasing output without increasing, has become a new topic.

\section{The Concept of the "Internet + "}

Domestic "Internet +" concept put forward, the earliest dating back to November 2012 to speak to Young in the fifth Analysys mobile Internet Expo. Analysys International chairman and chief executive officer Yang was first proposed in the "Internet +" concept. He said, "In the future, the" Internet + "formula should be our industry where products and services, such a chemical formula after a cross-platform user scenarios seen in conjunction with our future multi-screen generated by the entire network, we can follow such idea to find a number of such thoughts. And how to find your industry "Internet +", it is the companies need to think about [2].

\section{The Basic Connotation of "Internet +"}

"Internet + " is the integration of the two upgraded version of the Internet as a central feature of the current development of information technology, extracted, and full integration with the industrial, commercial, financial and other service sectors. This is where the key is innovation, only innovation can make this + really valuable and meaningful. Because of this, the "Internet + " is considered to be under 2.0 Internet innovation to develop new forms, new formats, is an evolution of the knowledge economy and society 2.0 social innovation driven by new forms of development. [3] Popular, "Internet +" is the "Internet + various traditional industries", but this is not a simple sum of the two, but the use of information and communication technologies and the Internet platform for Internet and traditional industries in-depth integration, create new development ecology.

\section{Presentation of the Export of Agricultural Products:}

Join the WTO in 2001 has brought opportunities for the export of agricultural products, with the gradual understanding of the international environment and preferential policies to encourage the WTO, China's exports of agricultural products to enter the stage of stable development. China's 
exports of agricultural products in the characteristics of stable development stage mainly for the following aspects:

The rapid growth of total exports in 2001, China's total agricultural exports of only $\$ 16.09$ billion, and by 2011, China's total agricultural exports reached $\$ 60.13$ billion, an average annual increase of $\$ 4.4$ billion, an average annual growth rate of $14.09 \%$.

Gradually concentrated export partner after joining the WTO, China's exports of agricultural products to developed country trading partners gradually centralized and regions. In 2011, only Japan, the United States, Hong Kong and South Korea four countries and regions, China's total exports accounted for $45.8 \%$ of all the year's total agricultural exports [4].

\section{The Affects of "Internet +" on the Export of Agricultural Products.}

Although the "Internet +" application in China's agriculture is still at an initial stage, but with the growing popularity of agricultural information, "Internet + " would have a more important impact on China's exports of agricultural products. Specific analysis is as follows:

Agricultural exports under greater pressure. Agriculture already withstand long-term downward pressure on agricultural prices. Farmers now before you buy or sell agricultural production, should advance through the network repeated buying and selling price comparison before deciding. Network so that farmers across geographical restrictions for the first time, or in the area of business activities in the country, so that agricultural prices situation more severe.

Network enables farmers to improve production management. Many agricultural sites have to forecast crop prices and offer financial services combined with electronic commerce, so farmers planting plan can be determined through the network, including the planting of crops and how much planting as well as what may be sold and at what price. Planting plan need to order seeds, fertilizers and other products contract, can be signed online.

Use the Internet to improve agricultural productivity: the modern farmer can use a global positioning system, aerial and satellite photography and other sensors to collect large amounts of agricultural data. Some sites specifically for farmers to effectively use all the data provided by the recipe service, the idea is to combine agricultural data with other types of information, including weather forecasting, environmental regulations, pest alerts. Farmers could then processes the data and can compare their experiences with planting approach other farmers. Increased productivity helps produce high-quality products.

\section{The Strategies of Agricultural Products Exports in the Background of "Internet +"}

Product strategy. In the Internet-based network marketing, agribusiness products and services should be targeted, its product form, product positioning and product development to reflect the characteristics of the Internet. Although multimedia technology can fully vividly demonstrated the characteristics of products, but not directly try, but also to the delivery of traditional commercial distribution channels or by courier. Therefore, the network marketing products and services should try to be information products and services, standardization of products before buying decisions need to try the product and be conducive to online sales. Positioning the product characteristics, income levels and education levels are high Internet users, like innovation, high-tech products for computer products and a soft spot „, to consider whether computer-related products and services, whether they are high-tech. In product development, agricultural enterprises can quickly provide new products to the customer structure, performance and other aspects of information and market research, customers can timely feedback to agricultural enterprises, thereby greatly improving 
agricultural companies to develop new products speed, also reduces the cost of developing new products [5].

Price strategy. Agricultural enterprises but also through the Internet, to provide information about product pricing, such as production costs, cost of sales, the establishment of price justification system for product pricing provide reasons, and responded to consumer inquiries, so consumption who agree product prices. In addition, the network marketing to provide products and services prices are still to be based on the elasticity of demand to develop products and services, while also considering network marketing features.

Promotion strategy. Network marketing promotion strategy aims to make the promotion more reasonable, consumers can take the initiative to search for the letter through the Internet, and agribusiness can be more focused on the target customer. Internet marketing has advantages in providing support. Through the Internet, consumers around the world can contact and communicate with the agricultural enterprises, customers can directly ask questions related to agribusiness products and services, as well as other agricultural enterprise application text, pictures and graphics display technology content of products and services to customers, explain, answer customer consulting, pre-sales and after-sales service in a timely manner so that the whole clear.

\section{Conclusion:}

Agricultural seems farthest from the Internet, but the potential of the "Internet + agriculture" is huge. Agriculture is the most traditional Chinese basic industries, an urgent need to enhance the efficiency of agricultural production with digital technology, through information technology to land soil fertility, climate and other large data analysis, and thus provide planting, fertilizing related solutions, greatly enhance agricultural productivity. In addition, Internet-based agricultural information needs of the market will help the docking, the new Internet era farmers can not only use the Internet to get advanced technical information, you can master the latest agricultural prices through big data, to determine the focus of agricultural production. At the same time, agriculture electricity providers will promote agricultural modernization process, reduce intermediate links the sale of agricultural products through the Internet trading platform, increasing farmers' income. Faced with more than one trillion yuan of agricultural markets and rural population of nearly seven hundred million users, the agricultural electricity providers face a huge market space.

\section{References}

[1] F.Jing, X.Q.Han, G.Pan. The size, structure and competitiveness of China export trade, J. Jiangsu rural economy. 11(2009) 64-65.

[2] L.Chen, Z.N.Lu, The international competitiveness of China's agricultural trade, J. Anhui Agricultural Sciences. 31(2007)10135-10140.

[3] G.H.Long. Chinese agricultural trade development bottleneck and countermeasures after WTO,J. Rural Economy and Science. 3(2008) 44 - 45.

[4] W.J.Zhong. Current situation analysis and countermeasures agricultural trade,J. Monthly price. 5(2007) 56-58.

[5] W.Tong, B.Tong. The current situation of agricultural trade and countermeasures,J.Market Modernization.34 (2008) 8-9. 